\title{
La inclusión como quehacer pedagógico
}

\section{Inclusion as a pedagogical work}

\author{
Martha Liliana González Restrepo *
}

\section{Presentación}

La educación inclusiva significa atender con calidad y equidad las características comunes y específicas que presentan nuestros niños y niñas. Para ello, la Experiencia Educativa aeioTU propone momentos cotidianos organizados, que se desarrollan a lo largo del día y cotidianamente llamamos "un día aeioTU".

\section{Contexto de la experiencia}

La inclusión hace parte de nuestra experiencia educativa, su intencionalidad radica en preparar a nuestros niños y niñas para que sean seres transformadores y propositivos mediante diversas experiencias enriquecedoras. Promovemos el arte como herramienta de aprendizaje, lo que permite habitar vivencias inagotables en las que niños y adultos son partícipes, y la imaginación, el arte y el juego son constantes para facilitar dicho aprendizaje.

Nuestros principios se enfocan en reconocer y valorar a nuestros niños y niñas, no los margina, sino, todo lo contrario, constantemente los relaciona con su familia, maestras, ambiente, entorno y sociedad en general.

Coordinadora General Centro aeioTU Aures, mgonzalez@aeiotu.org 


\section{Nuestra experiencia educativa se caracteriza por:}

- La transformación social que propone en el entorno en el que se desarrolla.

- Recoger los valores culturales en los que están insertos nuestros niños y niñas.

- La capacidad de observación y escucha que se vive a diario por parte del adulto que acompaña.

Es así como nuestros maestros y maestras rompen los esquemas rutinarios $y$ proponen procesos creativos para que el arte se convierta en el facilitador que activa el sentido de la vida y de las cosas. De esta manera, el arte es un eje central que atraviesa toda experiencia educativa, la cual es mediada y mirada desde un asunto creativo, libre y espontáneo.

Esto permite, como lo argumenta Loris Malaguzzi (1993), en el poema "Los cien lenguajes del niño”, allí alude a las múltiples formas que tiene un niño para expresarse y para encontrar un profundo sentido de lo que le interesa. Un dibujo no sólo es la expresión plástica sino la expresión en su máximo significado, es allí donde se articulan los cien lenguajes sin la separación que regularmente pretendemos y queremos ver los adultos en las diversas disciplinas.

En el centro aeioTU Aures, no hay restricciones en la participación de las niñas y los niños. Aun para aquellos en los que se han identificado retos de índole físico, cognitivos o emocional, por el contrario, hemos encontrado respuestas que les permitan vivir las rutinas del centro como cualquiera de sus compañeros; por lo tanto, valoramos y respetamos la diferencia como característica innata de cada ser, es preciso ser flexibles con el proceso de aprendizaje de cada uno de los que habita este espacio.

\section{Resultados}

A propósito de la participación en el diplomado "Estrategias de atención a la diversidad”, orientado por el Tecnológico de Antioquia, mediante convenio con la Fundación Saldarriaga Concha y el Programa Buen Comienzo de la Alcaldía de Medellín, podemos decir que el proceso de fortalecimiento nos permitió:

- Encontramos en la caracterización de la diversidad de nuestros niños y niñas, habilidades destacadas en la capacidad corporal y la capacidad de expresión, un reto para contrarrestar el impacto de la violencia del contexto en los comportamientos de los niños y niñas, y una posibilidad para encontrar estrategias para dar un rumbo diferente en la atención de los niños más vulnerables.

- En cuanto al análisis de políticas, culturas y prácticas concluimos que nuestra experiencia educativa es apropiado para dar respuesta a la diversidad, hace visibles las barreras y los mecanismos facilitadores en la atención a la diversidad no sólo en nuestros niños y niñas, sino también en los agentes educativos con quienes tienen hoy el reto de trabajo.

\section{Proyecciones}

A partir de los resultados nos queda un plan lleno de retos: 
- Revisar nuestras prácticas con énfasis en la identificación de las características de aprendizaje y estrategias desde el diseño universal para el aprendizaje.

- Sensibilizar a los niños, niñas y agentes educativos frente al buen trato, de manera que se fortalezcan los valores

- Fortalecer las redes interinstitucionales y el trabajo en equipo para el beneficio de todos los niños y las niñas.

- Realizar adecuaciones físicas que favorezcan el acceso de cualquier persona.

\section{Referencias}

Malaguzzi, Loris. (1993). Poema "los cien lenguajes de los niños y las niñas”. Recuperadodehttp://www.xtec.es/ jfernanq/ ee2005/100llenguatges.htm 
